\title{
Assessing the benefits and risks of owning a pet
}

\author{
E. Paul Cherniack MD, Ariella R. Cherniack
}

See also page 736 and www.cmaj.ca/lookup/doi/10.1503/cmaj.141020

$\mathrm{S}$ ome 7.5 million Canadian households, or $57 \%$ of the population, own at least one animal. ${ }^{1}$ Pet ownership rates peak in middle age and are lowest among older adults, but $39 \%$ of households with members older than 65 years still own a pet. ${ }^{1}$

In a linked review, Stull and colleagues discussed the medical risks of pet ownership. ${ }^{2}$ Although zoonotic infections are a possible risk of animal contact, the greatest burden of risk of disease transmission from domestic animals is among farmers in developing countries. Stull and colleagues affirmed that zoonotic infections acquired from pets are uncommon, highlighted the most important pathogens and suggested strategies to reduce the risk of transmission.

Despite the possible harms, millions of people still decide to own a pet, and whether pet ownership is a health advantage or harm depends on whether the perceived benefits outweigh the risks. Although the quality of much of the research in this area is variable owing to suboptimal study design and the presence of confounders, we discuss the benefits of pet ownership, including improvements in cardiovascular outcomes and the mental health of children, adults and seniors.

Owning a pet may increase physical activity. Several surveys and prospective studies have shown that adults who own a pet exercise more and participate in more leisure-time physical activity. ${ }^{3}$ A large Californian study found that people who owned a dog walked more as a leisure-time activity and walked almost $20 \mathrm{~min}$ utes more each week than people who did not own a pet. ${ }^{4}$ In a retrospective investigation involving more than 400 participants, dog owners had greater survival after 12 months than people who did not live with dogs, but cat owners did not live longer than participants who did not have a cat. ${ }^{5}$

Better cardiovascular health may be another benefit of pet ownership. Weak evidence suggests that pet ownership has physiologic benefits. Pet owners who received an implantable defibrillator had a lower risk of death more than two years after myocardial infarction than recipients with no pets. ${ }^{6}$ In another retrospective survey, pet owners admitted to hospital for an acute coronary syndrome had reduced cardiac morbidity and mortality up to one year after discharge. ${ }^{7}$ The American Heart Association scientific statement on cardiovascular risk states that pet ownership, particularly dog ownership, may reduce cardiovascular disease risk (evidence grade IIb).

Pet ownership may not be appropriate for all patients with mental illness, but animal-assisted therapy may support mental health. Several investigations have implied a benefit for children with autism or development disorders, and for children who have been abused. Dogs enhanced communication skills in 40 children with developmental delay beyond that in the presence of toys, and the children showed greater environmental awareness. ${ }^{8}$ Riding horses for 24 weeks improved behaviour ratings in a group of 20 children with autism. ${ }^{9}$ Animal-assisted therapy decreased traumatic symptoms in 153 children who had been sexually abused. ${ }^{10}$

In addition, animals may alleviate symptoms in adults with mental illness. In several small case series and self-controlled studies, patients with cognitive and mental impairments showed less behavioural disturbance or greater socialization behaviours in the presence of animals. ${ }^{3}$

These benefits continue at older ages; most studies, although not all, suggest a greater advantage with animal-assisted therapy. ${ }^{3}$ A study evaluating animal-assisted therapy in 65 nursing home residents with dementia showed stabilization of

\section{KEY POINTS}

- Most Canadian households have a pet, which suggests that people find pets beneficial, and some evidence suggests that owning a pet enhances health.

- Owning a dog may encourage physical activity, which may contribute to improved cardiovascular health.

- Contact with animals can confer psychological benefits, relieving symptoms of mental or cognitive illness and loneliness.

- Studies on the effect of animals on patients have been small and methodologically suboptimal. 
symptoms of depression and agitation over two and a half months when residents participated in weekly 45-minute sessions in which they petted and groomed a therapy dog. ${ }^{11}$ Patients who received "usual treatment" showed worsening symptoms. ${ }^{11}$ In addition, contact with animals, including pets, has social benefit and reduces loneliness.

However, given the frequency of our interactions with pets, the totality of evidence supporting their benefits is perhaps underwhelming. Many studies involve small sample sizes, have short follow-ups and do not consider potential harms.

Stull and colleagues' review may help further reduce such harms by discussing the important role physicians play in the dissemination of preventative information about animal contact, the detection of zoonotic infections and judicious history taking about exposures. For most patients, proper hand hygiene and appropriate animal husbandry are sufficient to prevent the transmission of pathogens. For people who are at high risk, such as children, immunocompromised patients, older adults and pregnant women, additional precautions are recommended.

One potential high-risk group not mentioned by Stull and colleagues is patients with cognitive impairments or mental illness. The prevalence of pet ownership or contact among such patients is unknown. Further investigation involving this particular group's risk for zoonotic harm and traumatic injury from bites or falls (such as when patients trip over their pets or leashes) is needed. In addition, many people with cognitive impairment or severe mental illness live with others who have similar problems, and the risks to these individuals are not known.

In addition to the potential improvement in cardiovascular and mental health that research thus far implies, pets may provide patients who have physical and mental disabilities or chronic pain similar functional, psychological and social benefits to those of service animals. ${ }^{12}$ Several studies suggest patients receiving treatment that includes therapy dogs show improved pain scores. ${ }^{12}$ For most people, however, the benefits of pet ownership remain intangible.

\section{References}

1. Consumer corner: Canadian pet market outlook, 2014. Edmonton: Alberta Ministry of Agriculture and Rural Development Available: www1.agric.gov.ab.ca/\$department/deptdocs.nsf/ all/sis14914 (accessed 2015 Feb. 27)

2. Stull JW, Brophy J, Weese JS. Reducing the risk of petassociated zoonotic infections. CMAJ 2015 Apr. 20 [Epub ahead of print].

3. Cherniack EP, Cherniack AR. The benefit of pets and animalassisted therapy to the health of older individuals. Curr Gerontol Geriatr Res 2014;2014:623203.

4. Yabroff KR, Troiano RP, Berrigan D. Walking the dog: Is pet ownership associated with physical activity in California? $J$ Phys Act Health 2008;5:216-28.

5. Friedmann E, Thomas SA. Pet ownership, social support, and one-year survival after acute myocardial infarction in the cardiac arrhythmia suppression trial (CAST). Am J Cardiol 1995;76:1213-7.

6. Friedmann E, Thomas SA, Son H. Pets, depression and long term survival in community living patients following myocardial infarction. Anthrozoos 2011;24:273-85.

7. Parker GB, Gayed A, Owen CA, et al. Survival following an acute coronary syndrome: a pet theory put to the test. Acta Psychiatr Scand 2010;121:65-70.

8. Martin F, Farnum J. Animal-assisted therapy for children with pervasive developmental disorders. West J Nurs Res 2002;24:657-70.

9. Kern JK, Fletcher CL, Garver CR, et al. Prospective trial of equine-assisted activities in autism spectrum disorder. Altern Ther Health Med 2011; 17:14-20.

10. Dietz TJ, Davis D, Pennings J. Evaluating animal-assisted therapy in group treatment for child sexual abuse. J Child Sex Abus 2012;21:665-83.

11. Majic T, Gutzmann H, Heinz A, et al. Animal-assisted therapy and agitation and depression in nursing home residents with dementia: a matched case-control trial. Am J Geriatr Psychiatry 2013;21:1052-9.

12. Winkle M, Crowe TK, Hendrix I. Service dogs and people with physical disabilities partnerships: a systematic review. Occup Ther Int 2012;19:54-66.

Affiliations: Division of Geriatrics and Palliative Medicine (Cherniack EP), University of Miami Miller School of Medicine, Bruce W. Carter Miami VA Medical Center, Miami, Fla.; Sha' arei Bina Torah Academy for Girls (Cherniack A), North Miami Beach, Fla.

Contributors: E. Paul Cherniack wrote the original draft of the manuscript. Ariella Cherniack revised the manuscript for important intellectual content. Both of the authors approved the version to be published and agree to act as guarantors of the work. 